\title{
Cooperación y desarrollo territorial en el espacio fronterizo del norte de Marruecos*
}

\author{
Enrique López Lara**
}

\begin{abstract}
Resumen. El norte de Marruecos, espacio regional fronterizo con España y la Unión Europea, es objeto de un intenso proceso de fomento de políticas y de programas de cooperación de diversas instituciones (ONU, Unión Europea, agencias de cooperación, entre otras) que poseen intereses en la zona, como son: fortalecimiento de un anillo de seguridad en un espacio estratégico, crecimiento de la renta por la existencia de un elevado escalón entre vecinos, creación de una nueva política de vecindad basada en la semiintegración, reducción de la emigración, etcétera. Cuestión que coincide con una decidida política del gobierno marroquí de relanzar socioeconómicamente este espacio: proceso de regionalización y dotación de instituciones (Agencia para la Promoción del Desarrollo en las Regiones del Norte), diseño de una estrategia de crecimiento basada en el desarrollo humano, y otras más. En este documento se analizan las razones de este proceso, la realidad geográfica y la caracterización socioeconómica del espacio fronterizo y se diagnostican debilidades y oportunidades para la articulación de las políticas de cooperación de los diferentes actores que buscan un desarrollo territorial de este espacio fronterizo hoy en crisis.

Palabras claves: norte de Marruecos, frontera, cooperación, política europea de vecindad, desarrollo territorial, desarrollo humano
\end{abstract}

Abstract. The North of Morocco, like border regional space with Spain and the European Union, is object of an intense process of promotion of policies and programs of cooperation of diverse institutions (UN, European Union, agencies of cooperation, among others) that have interests in the zone, such as: fortification of a growth, safety ring in a strategic zone of the rent by the existence of a high step between neighbors, creation of a new policy of vicinity based on semi-integration, reduction of the emigration, etcetera. Question that agrees with a determined policy of the Moroccan government to relaunch socially and economically this space: process of regionalización and dowry of institutions (Agency for the Promotion of the Development in the Regions of the North), design of a strategy of growth

* Trabajo inserto en la Cooperación con Marruecos: cursos de posgrado (AACI, 2004) en la Universidad Abdelmalek Esaadi de Tánger-Tetuán y proyectos de investigación con la Universidad Sidi Mohamed Ben Abdelah de Fez (AECI, 2006 y 2007). Asimismo, es producto de trabajos de campo del Master Erasmus-Mundus "Estudios Urbanos en Regiones Mediterráneas" (aprobado por la Unión Europea en noviembre de 2006) entre las Universidades de Sevilla, Marsella, Génova y Lisboa, teniendo como asociadas diversas universidades del Magreb (Marruecos, Argelia y Túnez).

** Profesor titular de Geografía. Universidad de Sevilla. Correo electrónico: elopezl@us.es 
based on the human development, and more. This paper analizes the reasons of this process, the geographic reality and the socioeconomic characterization of the border area. At the same time, it diagnoses the weaknesses and opportunities for the joint of new policies of cooperation and development for the actors who look for a territorial development in this border area, today in crisis.

Key words: north of Morocco, border, cooperation, European Neighbourhood Policy, territorial-development, human development

\section{Introducción: objetivos y método}

Las vicisitudes históricas, la proximidad y vecindad con Europa, su papel actual dentro del Mundo Árabe, la situación geoestratégica y las condiciones geopolíticas, entre otros motivos, convierten a Marruecos en un país de notable interés en los contextos internacional, euromediterráneo y magrebí.

A la par, el norte de Marruecos, espacio fronterizo con España y la Unión Europea, está adquiriendo en los últimos años una renovada dimensión socioeconómica, geoestratégica y territorial a diferentes niveles en función de múltiples razones, entre las que cabe destacar:

1. Los efectos del proceso de globalización, en especial en su dimensión económica, que refuerzan su carácter de encrucijada de caminos (cercanía geográfica con Europa y paso estratégico) a la vez que su papel de espacio excluido (López Lara, 2001).

2. Las variantes geopolíticas y geoeconómicas (derivadas de su posición estratégica en el Estrecho de Gibraltar) hacen que confluyan intereses a distintas escalas: internacional (Unión Europea), mediterránea (España y Francia, en especial) y regional (Andalucía, Canarias).

3. La apertura de una brecha entre ambos lados del Estrecho en los planos económico y social, junto al fenómeno de la emigración. El escalón económico entre países vecinos es de los más acusados y crecientes del mundo (Moré, 2003), agravado si se compara con las regiones del Norte, por debajo de la media del propio desarrollo humano del país.

4. La nueva situación política marroquí, con la potenciación institucional de los territorios septentrionales: proceso de regionaliza- 
ción y creación de una Agencia de Promoción del Desarrollo de las Prefecturas del Norte (APDN, 2005), construcción del Puerto TangerMed y aplicación de medidas de diversa índole (Iniciativa Nacional de Desarrollo Humano, promoción turística, creación de Zonas Francas, facilidades para la instalación de industrias foráneas, etcétera).

5. El auge del fundamentalismo en los países islámicos, de entre los que Marruecos y su parte norte no están exentos, aunque derive en matices y situaciones diferenciadas.

6. La importancia que el turismo en sus diversas modalidades y el patrimonio -natural, arqueológico, etnográfico, histórico-artístico- poseen en la región de cara a su desarrollo e imagen.

7. Su especial relevancia dentro del Proceso Euromediterráneo iniciado en Barcelona (1995), hoy en transformación al insertarse en la Nueva Política Europea de Vecindad (CEE, 2004).

8. El Estrecho de Gibraltar, en la actualidad y analizados los aspectos anteriores, sitúa a la región y su futuro inmediato en una dicotomía: entre la formación de un espacio fronterizo conflictivo o de un espacio transnacional (El Houdaigui, 2005).

Los efectos negativos que se derivan de su actual papel como espacio de exclusión o marginal (a escala internacional, euromediterránea y marroquí), el incremento de las diferencias económicas entre vecinos, las posibles convulsiones por desigualdades y carencias básicas, el fenómeno creciente de la emigración, los intereses económicos contrapuestos (con las derivaciones del esquema "contrabando, droga, emigración") a la par que las preocupaciones ante el empuje del fundamentalismo islámico son causas, entre otras, de la creciente preocupación por la seguridad y estabilidad de la región (CEE, 2004) y de la generación de una ola de cooperación (a diferentes niveles y con variado signo institucional) que fija sus objetivos en el norte de Marruecos. Además, como se ha indicado, la región septentrional es objeto de especial predicamento de la renovada política de fomento del gobierno marroquí.

Los ensayos, las prácticas y las realidades de los proyectos de cooperación en estas regiones poseen una especial relevancia y una re- 
percusión tridimensional: europea (Política Europea de Vecindad), española (relaciones fronterizas, estratégicas, económico-comerciales, culturales) y marroquí (política de equilibrio territorial, incremento del desarrollo humano, crecimiento en los procesos democráticos y del poder participativo de las regiones).

Una batería de proyectos de cooperación al desarrollo está viendo la luz en los últimos años en la zona norte de Marruecos, a la vez que se toman medidas para su impulso socioeconómico dentro de las estrategias de desarrollo del país magrebí.

Proyectos de cooperación al desarrollo que se han ido produciendo sin patrón referencial, a impulsos frecuentemente descoordinados, duplicándose los esfuerzos y, a veces, dejando territorios y sectores sin cubrir. No es de extrañar que en los cinco últimos años se hayan diseñado caminos para aunar esfuerzos y lograr una coordinación y una vertebración tanto vertical (entre y en las instituciones cooperantes) como horizontal (delimitación y catalogación de espacios geográficos y de temas sectoriales de acción).

Este artículo tiene tres objetivos fundamentales. El primero consiste en analizar el papel que asumen cuatro proyectos de cooperación recientes con incidencia directa en el desarrollo territorial de la zona: el proyecto Gold Magreb (PNUD, 2005), la Nueva Política de Vecindad de la Unión Europea (CEE, 2004), la estrategia de cooperación española (AECI, 2005b), y el Programa de Desarrollo Transfronterizo Andalucía- Marruecos (PDTAM , 2003).

El segundo objetivo se centra en analizar y diagnosticar las potencialidades y las debilidades de cara al desarrollo territorial de las regiones del Norte, deducidas mediante un método triple:

a. Tratamiento de entrevistas cualitativas realizadas a actores institucionales: Agencia para la Promoción del Desarrollo en las Regiones del Norte, Asociación Rif Andalus para el Desarrollo Local, Fundación al Idrissi, Universidades Abdelmalek Essaadi de Tetuán-Tánger y Sidi Mohamed Ben Abdelah de Fez, representantes de entidades rurales, directores de museos, miembros de los Institutos Cervantes y de los consulados de España en Tánger y Tetuán, ONG que trabajan en la zona, etcétera. 
b. Trabajo de campo recorriendo la zona en estudio, analizando y cotejando sobre el terreno debilidades y potencialidades.

c. Consulta de los proyectos de cooperación llevados a cabo en la zona en estudio.

En función de ello, se han confeccionado unos cuadros de debilidades y potencialidades, de factores y elementos claves de cara al desarrollo territorial.

El tercer objetivo es aportar elementos de reflexión (retos y oportunidades) para el debate sobre la validez de la puesta en marcha de procesos de potenciación del desarrollo territorial en zonas fronterizas, entendido como la búsqueda de un modelo de desarrollo que haga compatible la competitividad económica (desarrollo económico), el bienestar social (desarrollo social), la sustentabilidad ambiental (desarrollo sostenible) y la reducción de los desequilibrios territoriales (cohesión territorial).

\section{Condiciones geográficas y socioeconómicas del norte de Marruecos}

La reciente institucionalización de las regiones de Marruecos supone un hito clave para el reconocimiento oficial de los territorios septentrionales, marginados por los acontecimientos históricos y la política (interior y exterior) marroquí.

No existe suficiente perspectiva temporal para valorar si el proceso de regionalización marroquí de marzo de 1997 camina hacia una desconcentración del poder y hacia una real descentralización política y económica. La regionalización es inseparable de la participación ciudadana y de la democracia (Ojeda García, 2002), por lo que el papel de la sociedad civil con sus asociaciones a escala regional y con sus demandas y reivindicaciones locales va a resultar decisivo (López García y Berriane, 2004).

Desde la perspectiva geográfica, el norte de Marruecos es un territorio bañado por el Mediterráneo y el Atlántico, con una notable correspondencia en sus límites con lo que antaño fuera la zona del Protectorado Español, derivado de la Conferencia de Algeciras (Nogué y Vilanova, 1999). 
Figura 1.

Mapa administrativo: regiones de Marruecos

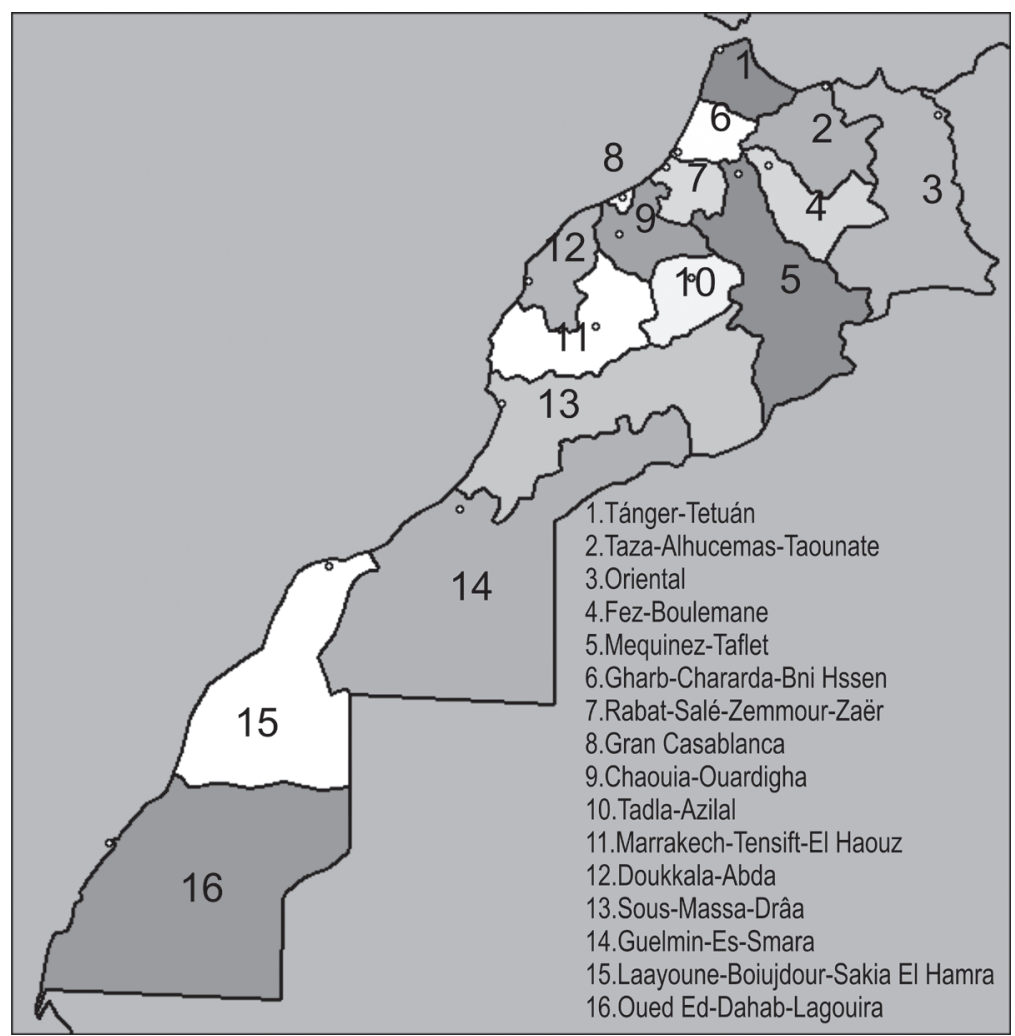

Fuente: www.rdh50.ma

El norte de Marruecos (figura 1), al que se le dota de una Agencia para la Promoción y el Desarrollo de las Prefecturas del Norte (APDN), queda delimitado y subdivido en tres regiones, que de oeste a este son (Ministère de l'Aménagement du Territoire, de l'Environnement de l'Urbanisme, et de l'Habitat, 2000): región de Tánger-Tetuán (número 1 del mapa), región de Taza-Al Hoceima-Taounate (número) y región Oriental (número 3).

Éste es el territorio considerado, haciendo especial inflexión en la primera de las regiones apuntadas, no sólo por ser la más poblada y 
la más cercana geográficamente a Europa, sino por las peculiaridades que ofrece de cara a su propio desarrollo regional, territorial y local y por las incidencias que tiene en el contexto fronterizo.

La región de Tánger-Tetuán engloba tres provincias (Chefchaouen, Larache y Tetuán) y dos prefecturas (Tánger-Asilah y Fahs-Beni Makada). Con una población de unos dos millones de habitantes (8 $\%$ de la población marroquí), tiene una densidad de $176 \mathrm{~h} / \mathrm{km}^{2}$, lo que supone cinco veces la media del país $\left(37 \mathrm{~h} / \mathrm{km}^{2}\right)$, y en ella predomina el poblamiento urbano (60\%). La agricultura y la pesca $(43.5 \%)$, el comercio (14.4\%) y la industria y el artesanado (13.7\%) son las principales actividades económicas. La tasa de crecimiento urbano es elevada (un 4.09\% de media), destacando el crecimiento del litoral tetuaní, con los muncicipios de Martil (8.01\%) y de M'diq (12.98 por ciento).

La región Taza-Al Hoceima-Taounate engloba las tres provincias con idéntica denominación, donde vive un $6.6 \%$ de la población marroquí, presentando un marcado carácter rural con un $78.4 \%$ de población rural y una economía que se basa fundamentalmente en la producción agrícola, destacando también por sus potencialidades de cara al desarrollo de actividades ecoturísticas (Tribak y otros, 2006).

La región Oriental aglutina las cinco provincias más al noreste (Jerada, Berkane, Taourirt, Figuig y Nador) más la prefectura de Oujda-Angad, englobando al $6.7 \%$ de la población de Marruecos. El sector terciario ocupa el $42 \%$ de la población activa, por encima del sector primario (34\%) y del secundario (21.4 por ciento).

Estas regiones representan 7\% del territorio marroquí y acogen a más del $21 \%$ de la población, es decir, a cerca de seis millones de personas (Alaoui Lamrani y otros, 2000; Reino de Marruecos, 2006).

Los principales procesos territoriales actualmente son: a) una intensa, constante y creciente urbanización, en especial en el litoral, poco y mal planificada; $b$ ) una agricultura en alza, en especial en el litoral, en constante conflicto con los usos residenciales y turísticos; c) un traspaís, el Rif, montañoso y rural, inmerso en una profunda crisis, con multitud de asentamientos rurales de suelos pobres vulnerables a la erosión, degradados por la presión demográfica (López Lara, 2001). 
Ha de apuntarse, asimismo, que las infraestructuras en general y las de transporte, en particular, son deficientes, enclavando la región en el contexto internacional y nacional marroquí, a la par que aislando a numerosos centros rurales y de montaña. A pesar de los abundantes recursos hídricos, las infraestructuras, pobres y deficitarias, no permiten un uso racional del agua.

El norte posee recursos naturales y potencialidades económicas aún por explotar de forma conveniente. Su economía se basa en el aprovechamiento agrícola, con los prejuicios del dominio de zonas de montaña y con las potencialidades de los recursos hídricos, en especial en los entornos de Taza (al este) y Larache (al oeste), con suelos y clima más favorables. Los recursos pesqueros se encuentran, asimismo, insuficientemente explotados y gestionados. La industria está escasamente desarrollada, si bien en la región Tánger-Tetuán ha crecido en la última década de la mano de la localización de industrias, en especial textiles, procedentes de países europeos. Otra de las potencialidades económicas de la región se centra en el turismo (López Lara, 2005), en alza en especial en torno al litoral mediterráneo tetuaní (Cabo Negro), de $\mathrm{Al}$ Hoceima y del litoral atlántico (Asilah).

La región septentrional marroquí, analizados los niveles de renta y los indicadores sociales (López Lara, 2001), se encuentra inmersa en una profunda crisis. Está necesitada de acciones y soluciones de diverso corte, ya que su crisis se proyecta sobre el marco regional, fronterizo e internacional, esto es, sus efectos traspasan sus propias fronteras.

\section{El norte de Marruecos: proyectos y estrategias de cooperación}

Desde los años noventa del pasado siglo, el norte de Marruecos viene siendo lugar común, objeto y punto de mira de políticas de desarrollo y de cooperación impulsadas por diversas organizaciones intergubernamentales, por la Unión Europea, por países a título individual (España, Francia, Alemania, Japón, Estados Unidos), por entidades regionales y locales, por ONGD y demás colectivos. La cooperación afecta al espacio regional en su totalidad, bien como unidad, bien en parte de sus territorios. Los campos y sectores para el fomento del desarrollo y la cooperación abarcan un abanico amplio y variado de aspectos (agricultura, 
sanidad, educación, infraestructura, agua, turismo, etc.), que buscan incentivar el desarrollo, en especial para evitar el fenómeno de la emigración (Bel Adel y Gómez Fayren, 2000).

Independientemente del éxito que se esté obteniendo, cuestión aún por evaluar, lo cierto es que el interés es compartido, no podía ser de otra forma, por el propio gobierno marroquí. El norte del Reino ha sufrido más que otras regiones la política económica de los ochenta -ajuste estructural-, de los noventa -liberalizaciones y privatizacionesy de principios del milenio -librecambio y asociaciones con Unión Europea y Estados Unidos- (Jerch, 2004) .

Tradicionalmente marginado, en el momento actual el espacio fronterizo del norte emerge por sus valores estratégicos y por sus propias y endógenas posibilidades de desarrollo, en especial las derivadas de su situación geográfica.

Es ineludible comentar que el norte de Marruecos es, asimismo, polo de atracción de otras opciones e instituciones que no centran sus estrategias en la cooperación por el desarrollo. En los últimos años, intereses empresariales y comerciales -la deslocalización estratégica de parte de los procesos productivos debida a una serie de ventajas (mano de obra barata, cercanía geográfica, potencialidad de apertura de mercados, incentivos fiscales, permisividad de la legislación ambiental, etc.)-, el desarrollo del turismo de masas basado en los valores del orientalismo cercano y en los recursos paisajísticos y naturales (López Lara, 2005), y valores geoeconómicos -futuro enlace fijo, gaseoductos, cable eléctrico submarino por el Estrecho de Gibraltar, entre otros- han aterrizado en la región inyectando nuevas perspectivas. No es el objetivo de esta aportación analizar dichos aspectos, si bien ha de hacer contrapeso en la balanza de intereses. Tampoco ha de obviarse el papel geopolítico que tienen en la zona la existencia de bases militares, las estrategias de seguridad y defensa, la presencia de Ceuta y Melilla, la delimitación de los espacios marítimo y aéreo (Suárez de Viveros, 2002), etcétera.

Los proyectos de cooperación al desarrollo puestos en marcha en el norte de Marruecos han sido diversos, escasamente coordinados y, en general, carecen de un referente territorial común. Baste decir que al día de hoy no existe un censo de la cooperación internacional (de hecho no hay una institución en Marruecos que se ocupe de ello, re- 
partiéndose la cuestión entre el Ministerio del Interior y el de Finanzas). Desde el 2005, la Agencia Española de Cooperación Internacional, en contacto con diversas instituciones internacionales, trabaja en la elaboración de un censo para conocer el tipo y la cuantía de ayuda que Marruecos recibe con el fin de inventariarla, coordinarla y darle visibilidad.

Los actores de la mencionada cooperación pueden encuadrarse de manera escalar: agentes internacionales tales como organizaciones intergubernamentales (PNUD): la Unión Europea (Política Europea de Vecindad); el estado español a través de la AECI con un programa marco dedicado al Mediterráneo y países árabes; diferentes Comunidades Autónomas, sobresaliendo las acciones de la Junta de Andalucía (Jordá Borrell, 2002), que ha llegado a diseñar un Programa de Desarrollo Transfronterizo (PDTAM, 2003); amén de las acciones de entidades locales $\mathrm{y}$, sobre todo, de organizaciones no gubernamentales y de la sociedad civil.

La mayor parte de las acciones se centran en los principios básicos de la cooperación al desarrollo, lucha contra la pobreza, mejora de las estructuras económicas y administrativas, aumento de la participación de la sociedad civil y búsqueda de un desarrollo sostenible y viable, todo lo cual busca reforzar el tejido productivo y promover el empleo, romper el aislamiento y fomentar la integración en el espacio euromediterráneo potenciando el equilibrio inter e intrarregional. A todas estas ayudas, llevadas a cabo de diferente forma y con variable dotación económica, hay que sumar los propios intereses y acciones del gobierno marroquí en la zona.

Al no existir un censo fiable y al pertenecer los sectores a una muy variada tipología, se hace necesario un replanteamiento en tres direcciones. En primer lugar, un planteamiento estratégico que coordine el conjunto de las acciones de cooperación en este espacio. En segundo lugar, un replanteamiento que otorgue primacía a la descentralización de la cooperación. Y, en tercer lugar, un nuevo enfoque que englobe el conjunto de acciones con las propias de la política social y económica del gobierno marroquí, que ha de caminar hacia la progresiva consecución de principios democráticos y una verdadera descentralización participativa. 
A continuación se reseñan cuatro iniciativas generadas en los últimos cinco años que marcan un cambio positivo en la concepción de la cooperación, benefician al norte de Marruecos por sus especiales caracteres (espacio fronterizo, bajos índices de desarrollo humano, existencia de potencialidades endógenas) y confluyen en los planteamientos anteriores.

\section{Programa Gold PNUD (Gold Maroc 2002-2006)}

El Programa Gold Maroc forma parte de la iniciativa Gold Magreb (Gobernanza Local y Desarrollo en el Magreb), inscrita en la iniciativa de Cooperación del Programa de las Naciones Unidas para el Desarrollo (PNUD, 2004). Se trata de una concertación estrecha entre el PNUD y el gobierno de Marruecos (diferentes ministerios), respondiendo a las prioridades formuladas en el Plan de Desarrollo Económico y Social (Ministère de la Prévision Économique et de la Planification, 2000).

Los objetivos básicos del Gold Magreb son: 1. asistir a los gobiernos, la sociedad civil y al sector privado en sus esfuerzos en los procesos de descentralización y desarrollo participativo integrado a escala local; y, 2. apoyar procesos de desarrollo local a través de la mejor utilización de los recursos de la cooperación internacional, de la cooperación descentralizada y de la cooperación sur-sur.

Los dominios de intervención que se consideran y apoyan financieramente son: el desarrollo económico local, la gobernanza local, la lucha contra la exclusión social y la promoción cultural. Además, incentiva la formación de asociaciones con esos objetivos entre los actores de los países del sur del Mediterráneo y los países europeos y del resto del mundo. El Gold Maroc pretende favorecer los intercambios comerciales, económicos, culturales, científicos y formativos con los países fronterizos o vecinos y la puesta en práctica de iniciativas temáticas de dimensión regional.

De esta forma, a través del programa Gold Maroc, y para el periodo 2002-2006 instrumenta una más que interesante vía de cooperación. Marruecos ha seleccionado una serie de territorios prioritarios o básicos para recibir ayudas de este Programa, entre los que se encuentran las regiones Tánger-Tetuán y Oriental (PNUD, 2005). 
El Gold Maroc ofrece a las autoridades locales un cuadro de referencia e instrumentos operacionales para establecer y facilitar asociaciones internacionales con el fin de contribuir lo más eficazmente posible a un desarrollo local durable, equitativo, pacífico y democrático. Se apoya en los programas de desarrollo local existentes o por crear, así como en instrumentos de planificación y coordinación que se creen, en especial aquellos que se compartan desconcentrada y descentralizadamente entre colectividades locales europeas y asociaciones locales y regionales marroquíes.

\section{La Nueva Política de Vecindad de la Unión Europea (PEV)}

Pocos días después de la ampliación de la Unión Europea hacia el Este (mayo de 2004), la Comisión presentó un documento estratégico, la Nueva Política Europea de Vecindad (CEE, 2004), que propone fortalecer los vínculos con los países vecinos, tanto del Mediterráneo Meridional como de Europa Oriental. Se parte de la idea de que lejos de establecer líneas divisorias con sus países vecinos, la Unión Europea debe crear incentivos y medios capaces de extender los beneficios de la integración, propiciando el desarrollo económico y la prosperidad.

El enfoque que se propugna con la PEV es interesante para Marruecos, en especial para las regiones del norte. La cooperación, más que sectorial, se entiende que debe estar basada en proyectos integrados de desarrollo territorial. Los actores posibles de los beneficios de la cooperación trascienden al propio gobierno marroquí, incorporándose agencias de desarrollo, consejos regionales, colectividades locales, etcétera.

Por una parte, la nueva PEV otorga prioridad a la necesidad de concentrar el esfuerzo de cooperación en las zonas fronterizas y próximas; y por la otra, avala un nuevo enfoque que supone la identificación, en un territorio dado, de un eje de desarrollo y de acciones estructurantes de acompañamiento, implicando al conjunto de actores en el marco de una estrategia específica de cooperación y de valoración de las ventajas competitivas, dentro de un planteamiento de desarrollo sostenible con participación de las colectividades locales y siempre con la voluntad y la incardinación dentro de la política socioeconómica del país objeto de cooperación. 
Tras el Informe 50 años de Independencia (Reino de Marruecos, 2006), Marruecos está cumpliendo sus deberes programáticos, entre los que destaca la promulgación en mayo de 2005 de la Iniciativa Nacional para el Desarrollo Humano (Martín, 2006).

A largo plazo, la PEV pretende la semiintegración en el mercado único y la participación en algunos de los programas y políticas comunes comunitarias (aunque sin derechos políticos) de aquellos espacios regionales fronterizos o vecinos. Se trata de una nueva visión y de una nueva oferta de cooperación, a cambio de avances concretos que demuestren la existencia de valores compartidos (democráticos, económicos, sociales) con un enfoque diferenciado por países.

La PEV plantea una cooperación que rompe con el esquema tradicional, pues desarrolla un enfoque diferenciado, gradual y por objetivos que se irán evaluando y que por tanto implican un avance monitorizado. El método propuesto consiste en definir conjuntamente con los países vecinos una serie de prioridades (acercamiento por cumplimiento a la UE) que se incorporan al Plan de Acción a fin de poder participar en el mercado único.

Los instrumentos financieros a aplicar por la PEV entran dentro del marco del nuevo periodo presupuestario que comienza en el 2007. A partir de este año, el nuevo Instrumento Europeo de Vecindad y Asociación financiará "programas conjuntos" entre varios países, tanto de cooperación transfronteriza como de cooperación regional, con la idea de aplicar las modalidades y procedimientos propios de los Fondos Estructurales.

En suma, la PEV es una concepción de la cooperación transfronteriza como instrumento de codesarrollo que se basa en el apoyo a la gobernanza y la democracia local y que da prioridad a la cooperación descentralizada.

\section{Plan Director AECI (2005-2008). Documento Estratégico Marruecos}

La cooperación española siempre ha otorgado a Marruecos un papel prioritario, en especial desde 1989, cuando se crea la Agencia Española de Cooperación Internacional (AECI). Han sido numerosos los esfuerzos realizados en múltiples campos, si bien no ha existido suficiente 


\section{Cuadro 1. Líneas estratégicas de la cooperación española. Documento Estratégico Marruecos 2005-2008}

\begin{tabular}{|c|c|c|}
\hline $\begin{array}{l}\text { Nivel de } \\
\text { prioridad }\end{array}$ & Objetivo estratégico & Líneas estratégicas en Marruecos \\
\hline 1 & $\begin{array}{l}\text { 1. Aumento de las capacidades } \\
\text { institucionales }\end{array}$ & $\begin{array}{l}\text { 1. Promoción de la democracia representativa } \\
\text { y participativa y del pluralismo político. } \\
\text { 2. Fortalecimiento del Estado de Derecho. } \\
\text { 3. Desarrollo de la Administración al servicio } \\
\text { de la ciudadanía y buena gestión de los } \\
\text { asuntos públicos. }\end{array}$ \\
\hline 1 & $\begin{array}{l}\text { 2. Aumento de las capacidades } \\
\text { humanas }\end{array}$ & $\begin{array}{l}\text { 1. Mejora del acceso universal a la educación. } \\
\text { 2. Mejora de la salud infantil. } \\
\text { 3. Derechos de la infancia. } \\
\text { 4. Atención a la juventud. } \\
\text { 5. Acceso al agua potable y saneamiento } \\
\text { básico. }\end{array}$ \\
\hline 1 & $\begin{array}{l}\text { 3. Aumento de las capacidades } \\
\text { económicas }\end{array}$ & $\begin{array}{l}\text { 1. Apoyo a la micro y pequeña empresa en el } \\
\text { ámbito de los sectores productivos prio- } \\
\text { rizados en el Plan Director } \\
\text { 2. Dotación de infraestructuras. }\end{array}$ \\
\hline 1 & $\begin{array}{l}\text { 6. Aumento de las capacidades } \\
\text { y autonomía de las mujeres }\end{array}$ & $\begin{array}{l}\text { 1. Mejora de las oportunidades de las muje- } \\
\text { res en el ámbito económico }\end{array}$ \\
\hline 2 & $\begin{array}{l}\text { 2. Aumento de las capacidades } \\
\text { humanas }\end{array}$ & $\begin{array}{l}\text { 1. Fortalecimiento institucional de los sistemas } \\
\text { públicos de salud. }\end{array}$ \\
\hline 2 & $\begin{array}{l}\text { 4. Aumento de las capacidades } \\
\text { para la mejora de la } \\
\text { sustentabilidad ambiental }\end{array}$ & $\begin{array}{l}\text { 1. Conservación y gestión sostenible de la } \\
\text { biodiversidad y los ecosistemas vulnera- } \\
\text { bles. }\end{array}$ \\
\hline 2 & $\begin{array}{l}\text { 6. Aumento de las capacidades } \\
\text { y autonomía de las mujeres }\end{array}$ & $\begin{array}{l}\text { 1. Fortalecimiento de las políticas y mecanis- } \\
\text { mos nacionales de igualdad de género. }\end{array}$ \\
\hline 3 & $\begin{array}{l}\text { 2. Aumento de las capacidades } \\
\text { humanas }\end{array}$ & $\begin{array}{l}\text { 1. Mejoramiento de áreas rurales precarias o } \\
\text { barrios marginales. }\end{array}$ \\
\hline 3 & $\begin{array}{l}\text { 5. Aumento de la libertad y de } \\
\text { las capacidades culturales }\end{array}$ & 1. Cooperación cultural para el desarrollo. \\
\hline
\end{tabular}

Fuente: AECI (2005b). 
coordinación, hecho que ha repercutido en la escasa visibilidad pese a los numerosos operadores de cooperación (Valencia, 2005).

En 2005, la Agencia Española de Cooperación Internacional renovó sus estrategias (Olmo García, 2006) instrumentando, entre otros, un proceso de planificación de sus acciones con la publicación del Plan Director de Cooperación 2005-2008 (AECI, 2005a). En éste se seleccionan las líneas estratégicas de intervención por países considerados de forma individual. Para cada país objeto de cooperación se realiza un Documento Estratégico donde se analiza la situación en términos de desarrollo, intentando que se canalice un proceso de concertación (coordinación y complementariedad) entre todos los actores de la cooperación.

El Documento Estratégico Marruecos 2005-08 (AECI, 2005b) delimita como zona prioritaria el norte del país (junto al eje urbano de Casablanca-Mohamedia-Rabat y la zona costera de la región de Souss Massa-Daara, incluyendo Agadir y Tiznit). Las líneas estratégicas prioritarias para Marruecos (cuadro 1) son: cobertura de necesidades sociales básicas, gobernanza democrática, desarrollo económico y género y desarrollo.

\section{Plan Desarrollo Transfronterizo Andalucía-Marruecos (2003-2006)}

La cooperación de la Junta de Andalucía con Marruecos se inicia a finales de la década de los ochenta. La política de cooperación al desarrollo de la Junta de Andalucía es de reseña especial, dado que los proyectos puestos en marcha están actualmente coordinados por las estrategias del Programa de Desarrollo Transfronterizo AndalucíaMarruecos (2003-2006), hoy en revisión para su renovación para el periodo 2007-2010, estableciendo una delimitación territorial y referentes básicos para el desarrollo.

El Programa de Desarrollo Transfronterizo Andalucía-Marruecos (2003-2006) es un instrumento innovador que dio paso a una nueva fase en las relaciones Andalucía-Marruecos. Se trata de superar el estadio de cooperación para iniciar el de asociación, siguiendo lo acordado en la Conferencia Euromediterránea de Barcelona del año 1995. Su objetivo sustancial es otorgar a las actuaciones de cooperación un 
carácter transfronterizo, participando de objetivos y orientaciones de la cooperación en el contexto de la Unión Europea.

Delimita un ámbito territorial preciso (el norte de Marruecos: región Tánger-Tetuán; región Taza, Alhucemas, Taounate; y región Oriental), estructurándose unos ejes prioritarios que poseen una óptica integradora. Además, considera la integración con los planes de desarrollo de Marruecos, ya que el programa está proyectado y cofinanciado conjuntamente entre la Junta de Andalucía y el Reino de Marruecos.

Siete son los ejes prioritarios: servicios sociales básicos (lucha contra la pobreza, educación y salud), desarrollo social (infancia, juventud, mayores, minusválidos, mujer y consumidores), desarrollo económico (agricultura y desarrollo rural, fomento de la economía social y del empleo, comercio interior, cooperación empresarial y turismo), infraestructuras (transportes, agua, ordenación del territorio y urbanismo), fortalecimiento institucional (formación de funcionarios de la administración local y regional e intercambio de experiencias en materia de descentralización), medio ambiente y energía, cultura y rehabilitación del patrimonio arquitectónico.

Partiendo de dichos presupuestos, esta investigación realiza trabajos de campo, entrevistas a actores institucionales (asociaciones locales, instituciones gubernamentales y no gubernamentales, universidades) tratando de aportar una óptica más de detalle, en lo territorial (región norte) y en lo económico (desarrollo territorial y local), que sirva para encuadrar de una manera coherente los diferentes proyectos de cooperación en el necesario desarrollo de la zona.

\section{Análisis-diagnóstico del desarrollo territorial en el norte de Marruecos}

En este apartado se efectúa un análisis-diagnóstico de las potencialidades y debilidades que las regiones del norte detentan de cara al desarrollo territorial. El estudio se sustenta sobre tres ejes: $a$ ) entrevistas a instituciones, actores y asociaciones regionales y locales (APDN, Asociación Rif Andalus, Fundación al Idrissi, Universidades Abdelmalek 
Essaadi de Tetuán-Tánger y Sidi Mohamed Ben Abdelah de Fez, alcaldes de entidades rurales, representantes de los Institutos Cervantes y consulados de España en Tánger y Tetuán, ONG que trabajan en la zona, etc.); b) trabajo de campo; y c) consulta de proyectos de cooperación en el norte de Marruecos.

Este método ha permitido elaborar una serie de cuadros de problemas y fortalezas detectadas delimitando factores y elementos clave para el desarrollo territorial (cuadros 2, 3, 4 y 5). Las potencialidades y debilidades se exponen sistemáticamente estructuradas en cuatro apartados: recursos naturales (cuadro 2), infraestructuras y equipamientos (cuadro 3), recursos humanos (cuadro 4) y estructura productiva y tejido empresarial (cuadro 5). Todas ellas coinciden en la necesidad de un mayor protagonismo de proyectos descentralizados que impliquen una mayor participación ciudadana y de la sociedad civil, auténtico reto en el actual Marruecos (Desrues, 2005).

\section{Retos y oportunidades. La importancia del "espacio de los lugares" y del desarrollo territorial como estrategia}

Una vez analizadas las potencialidades y debilidades de cara al desarrollo territorial, el tercer objetivo de este trabajo se centra en aportar elementos de reflexión al debate sobre la validez de la puesta en marcha de procesos de desarrollo territorial en zonas fronterizas.

Los nuevos designios que se implantan en la cooperación al desarrollo de los distintos programas analizados (descentralización, coordinación, política social y local, gestión del territorio a través de las capacidades y de mecanismos sociales) abren una etapa llena de retos y oportunidades para este espacio regional fronterizo marroquí.

Espacio fronterizo de valor estratégico, excluido y en crisis -pobreza, carencia de servicios básicos, aislamiento, chabolismo (Martín, 2005)- que en las últimas dos décadas está inserto en nuevos procesos internos (regionalización, dotación de instituciones regionales, nueva política social y una iniciativa de desarrollo humano) y externos (cooperación que busca incentivos para su desarrollo territorial). Estos procesos ponen a prueba la capacidad de este espacio fronterizo para integrarse en el sistema mundo (Castells, 1996). 


\section{Cuadro 2. Potencialidades y debilidades de los recursos naturales de las regiones del norte de Marruecos}

\begin{tabular}{|c|c|c|}
\hline $\begin{array}{l}\text { Recursos } \\
\text { naturales }\end{array}$ & Potencialidades & Debilidades \\
\hline Climatología & $\begin{array}{l}\text { - Confort climático. } \\
\text { - Fuerte irradiación solar. } \\
\text { - Elevada pluviometría. }\end{array}$ & $\begin{array}{l}\text { - Corriente seca y tórrida de aire } \\
\text { procedente del Sahara en verano. } \\
\text { - Vulnerabilidad a las } \\
\text { inundaciones por déficit de } \\
\text { embalses. }\end{array}$ \\
\hline Hidrología & $\begin{array}{l}\text { - Abundancia del recurso agua: } \\
\text { manantiales, acuíferos y fuentes } \\
\text { naturales. } \\
\text { - } \quad \text { Existencia de hábitat húmedo } \\
\text { propicio para la avifauna. } \\
\text { - } \\
\text { Presencia de aguas minero- } \\
\text { medicinales en las cumbres del Rif. }\end{array}$ & $\begin{array}{l}\text { - Insuficiente aprovechamiento del } \\
\text { recurso agua (déficit } \\
\text { infraestructural). } \\
\text { - } \\
\text { Sobreexplotación y } \\
\text { contaminación de los acuíferos } \\
\text { debido a las prácticas agrícolas } \\
\text { incontroladas. }\end{array}$ \\
\hline Geomorfología & $\begin{array}{l}\text { - Aparición de ecosistemas singulares } \\
\text { de alta montaña aptos para el } \\
\text { turismo rural. } \\
\text { - Abundancia de precipitaciones por } \\
\text { la altura. }\end{array}$ & $\begin{array}{l}\text { - Escasa aptitud agrológica como } \\
\text { consecuencia de las acusadas } \\
\text { pendientes. } \\
\text { - Alta erosividad. } \\
\text { - Dificultades para la instalación de } \\
\text { infraestructura. }\end{array}$ \\
\hline Vegetación & $\begin{array}{l}\text { - } \text { Gran biodiversidad. } \\
\text { - } \text { Aparición de numerosas especies } \\
\text { endémicas. } \\
\text { - } \\
\text { - } \quad \text { Arotección contra la erosión. } \\
\text { recursos (aplicaciones industriales). }\end{array}$ & $\begin{array}{l}\text { - Deterioro paulatino de la cubierta } \\
\text { vegetal (erosión). } \\
\text { - Escasa concienciación sobre la } \\
\text { protección ambiental. } \\
\text { - } \quad \text { Inadecuación de las leyes a la } \\
\text { realidad rural. }\end{array}$ \\
\hline Paisaje & $\begin{array}{l}\text { - Diversidad de paisajes en función } \\
\text { del dominio climático (montaña, } \\
\text { costa, etc.) } \\
\text { - Atractivo visual. } \\
\text { - Existencia de elementos naturales } \\
\text { singulares. }\end{array}$ & $\begin{array}{l}\text { - Deterioro del paisaje tradicional y } \\
\text { aparición de impactos visuales } \\
\text { (por ejemplo, construcciones no } \\
\text { adecuadas al entorno). }\end{array}$ \\
\hline
\end{tabular}

Fuente: Elaboración propia. 


\section{Cuadro 3. Potencialidades y debilidades de las infraestructuras y equipamientos. Regiones del norte de Marruecos}

\begin{tabular}{|c|c|c|}
\hline $\begin{array}{l}\text { Infraestructuras } \\
\text { Y equipamientos }\end{array}$ & Potencialidades & Debilidades \\
\hline Red de carreteras & $\begin{array}{l}\text { - Futuras mejoras para una } \\
\text { correcta conexión con el } \\
\text { Puerto MedTanger. } \\
\text { - Elevada recepción de } \\
\text { transportes de } \\
\text { mercancías. }\end{array}$ & $\begin{array}{l}\text { - Escasa integración en el territorio. } \\
\text { - Necesidad de planificación. } \\
\text { - Estructura simple, mal distribuida y } \\
\text { falta de cohesión. } \\
\text { - Red insuficiente para una adecuada } \\
\text { articulación regional. } \\
\text { - Deficiencias de calidad en el diseño y } \\
\text { firmes. } \\
\text { - Infrautilización de autopistas por los } \\
\text { costes. }\end{array}$ \\
\hline Red de ferrocarril & $\begin{array}{l}\text { - Futuras mejoras para } \\
\text { asegurar la correcta } \\
\text { conexión con el Puerto } \\
\text { MedTanger. } \\
\text { - Menor saturación que la } \\
\text { red de carreteras. }\end{array}$ & $\begin{array}{l}\text { - Trazado carente de planificación. } \\
\text { - Lento rejuvenecimiento. } \\
\text { - Estructura simple y sin cohesión. } \\
\text { - Mal estado de las vías. } \\
\text { - Escasa electrificación. } \\
\text { - Velocidad reducida. } \\
\text { - Obsolescencia de locomotoras y } \\
\text { vagones. }\end{array}$ \\
\hline Puertos & $\begin{array}{l}\text { - Extensa línea de costa. } \\
\text { - Recepción de la práctica } \\
\text { totalidad de los } \\
\text { intercambios exteriores de } \\
\text { Marruecos. } \\
\text { - Infraestructura portuaria } \\
\text { relativamente } \\
\text { diversificada. } \\
\text { - Construcción del Puerto } \\
\text { Tánger Mediterráneo } \\
\text { (dinamización } \\
\text { económica). } \\
\text { - Importancia de las } \\
\text { actividades industrial, } \\
\text { turística y comercial en el } \\
\text { actual puerto de Tánger. }\end{array}$ & $\begin{array}{l}\text { - Obsolescencia de los armadores y } \\
\text { escasa capacidad de tonelaje. } \\
\text { - Dedicación casi absoluta a la pesca } \\
\text { artesanal (a excepción del puerto de } \\
\text { Tánger). } \\
\text { - Equipamientos rudimentarios. } \\
\text { - Fuerte saturación de los tráficos de } \\
\text { pasajeros y mercancías en Tánger. } \\
\text { - Intensidad de la emigración } \\
\text { clandestina y del comercio } \\
\text { contrabandista. }\end{array}$ \\
\hline Aeropuertos & $\begin{array}{l}\text { - Cercanía al puerto de } \\
\text { Tánger (potenciación de } \\
\text { las relaciones } \\
\text { intermodales). } \\
\text { - Principal medio de } \\
\text { transporte de turistas que } \\
\text { proceden de países } \\
\text { lejanos. }\end{array}$ & $\begin{array}{l}\text { - Escasa distancia entre uno y otro } \\
\text { aeropuerto (planificación } \\
\text { inadecuada). } \\
\text { - Infrautilización de sus } \\
\text { infraestructuras. }\end{array}$ \\
\hline
\end{tabular}


Continuación...

\begin{tabular}{|c|c|c|}
\hline $\begin{array}{l}\text { Infraestructuras } \\
\text { Y equipamientos }\end{array}$ & Potencialidades & Debilidades \\
\hline Telecomunicaciones & $\begin{array}{l}\text { - Gran aceptación popular } \\
\text { de la telefonía móvil. } \\
\text { - Frecuentación de los } \\
\text { cybercafés por parte de la } \\
\text { población joven. }\end{array}$ & $\begin{array}{l}\text { - Monopolio de un único operador de } \\
\text { telefonía fija. } \\
\text { - Coste elevado de las conexiones. } \\
\text { - Escasos usuarios de telefonía fija y, } \\
\text { por ende, de Internet. } \\
\text { - } \text { Inexistencia de infraestructuras de } \\
\text { telecomunicaciones en el mundo } \\
\text { rural y serrano. } \\
\text { - Poca concienciación ciudadana de las } \\
\text { opciones económicas de Internet. }\end{array}$ \\
\hline $\begin{array}{l}\text { Infraestructuras } \\
\text { energéticas }\end{array}$ & $\begin{array}{l}\text { - Diversificación de las } \\
\text { fuentes de suministros y } \\
\text { valorización de los } \\
\text { recursos autóctonos. } \\
\text { - } \text { Aprovechamiento de la } \\
\text { velocidad media de los } \\
\text { vientos para la generación } \\
\text { de electricidad. } \\
\text { - Buena aceptación de las } \\
\text { placas solares. } \\
\text { - Acceso a la electricidad en } \\
\text { los medios rurales y } \\
\text { aislados gracias a } \\
\text { centrales hidroeléctricas. } \\
\text { - Posibilidad de generar } \\
\text { empleo rural con la } \\
\text { construcción de las } \\
\text { mismas. }\end{array}$ & $\begin{array}{l}\text { - Excesiva dependencia del exterior. } \\
\text { - Escaso consumo eléctrico. } \\
\text { - Dificultad de acceso de buena parte } \\
\text { de la población rural a la electricidad } \\
\text { y al agua potable. } \\
\text { - Elevado coste a la conexión eléctrica. } \\
\text { - Utilización poco controlada de la } \\
\text { biomasa para generar calor. } \\
\text { - Generación de multitud de desechos } \\
\text { domésticos no aprovechados a } \\
\text { posteriori. }\end{array}$ \\
\hline $\begin{array}{l}\text { Equipamientos } \\
\text { sanitarios }\end{array}$ & $\begin{array}{l}\text { - Crecimiento acelerado de } \\
\text { la oferta privada en las } \\
\text { grandes ciudades. } \\
\text { - Distribución homogénea } \\
\text { de la oferta pública. }\end{array}$ & $\begin{array}{l}\text { - Insuficiente atención médica, en } \\
\text { especial en el medio rural. } \\
\text { - } \text { Escaso personal sanitario. } \\
\text { - } \text { Cultura reacia a la demanda de } \\
\text { servicios médicos. } \\
\text { - Existencia de pocos equipamientos de } \\
\text { asistencia básica y pocas camas por } \\
\text { habitantes. } \\
\text { - Escasez de médicos especialistas. }\end{array}$ \\
\hline $\begin{array}{l}\text { Equipamientos } \\
\text { educativos }\end{array}$ & $\begin{array}{l}\text { - Interés del gobierno por la } \\
\text { educación (importantes } \\
\text { inversiones). } \\
\text { - } \text { Matrículas escolares en } \\
\text { aumento. } \\
\text { - } \text { Intensa actividad } \\
\text { económica conexa a las } \\
\text { universidades. }\end{array}$ & $\begin{array}{l}\text { - } \text { Calidad y cobertura débiles. } \\
\text { - Tasa de analfabetismo muy elevada, } \\
\text { sobre todo entre las mujeres del } \\
\text { medio rural. } \\
\text { - } \quad \text { Deficiente retención escolar } \\
\text { (abandonos prematuros). } \\
\text { - } \text { Inexistencia de equipamientos } \\
\text { educativos básicos en muchas } \\
\text { localidades. }\end{array}$ \\
\hline
\end{tabular}

Continúa... 
Continuación...

\begin{tabular}{|c|c|c|}
\hline $\begin{array}{l}\text { Infraestructuras } \\
\text { Y equipamientos }\end{array}$ & Potencialidades & Debilidades \\
\hline & $\begin{array}{l}\text { Educación como principal } \\
\text { factor de progresión de } \\
\text { las sociedades locales. }\end{array}$ & $\begin{array}{l}\text { - Gran distancia entre los hogares y las } \\
\text { escuelas. } \\
\text { - Educación en competencia con el } \\
\text { trabajo infantil. } \\
\text { - Absentismo escolar. }\end{array}$ \\
\hline Patrimonio & $\begin{array}{l}\text { - Urbanismo tradicional de } \\
\text { corte islámico. } \\
\text { - Edificios histórico- } \\
\text { culturales emblemáticos. } \\
\text { - Especialización en labores } \\
\text { artesanales. } \\
\text { - Contribución de la } \\
\text { artesanía a la economía. } \\
\text { - Riqueza gastronómica y } \\
\text { etnográfica. } \\
\text { - Yacimientos } \\
\text { arqueológicos. }\end{array}$ & $\begin{array}{l}\text { - Irrupción de nuevas construcciones } \\
\text { de corte occidental. } \\
\text { - Abandono del patrimonio histórico } \\
\text { de las ciudades. } \\
\text { - Bajo nivel y mantenimiento de los } \\
\text { museos. } \\
\text { - Estado de abandono de los } \\
\text { - yacimientos arqueológicos. } \\
\text { - Baja rentabilidad de la actividad } \\
\text { artesanal. }\end{array}$ \\
\hline
\end{tabular}

Fuente: Elaboración propia.

\section{Cuadro 4. Potencialidades y debilidades de los recursos humanos de las regiones del norte de Marruecos}

\begin{tabular}{|c|c|c|}
\hline & Potencialidades & Debilidades \\
\hline $\begin{array}{l}\text { Recursos } \\
\text { humanos }\end{array}$ & $\begin{array}{l}\text { - Reducción de la tasa bruta de } \\
\text { mortalidad. } \\
\text { - Dominio de las cohortes en } \\
\text { edad de trabajar. } \\
\text { - Renovación generacional } \\
\text { asegurada. } \\
\text { - Incipiente penetración de la } \\
\text { mujer en el mercado laboral. } \\
\text { - Uso cada vez más } \\
\text { generalizado de los métodos } \\
\text { contraconceptivos. } \\
\text { - Interés gubernamental por la } \\
\text { formación profesional. }\end{array}$ & $\begin{array}{l}\text { - Tasa de natalidad aún alta, en } \\
\text { especial en el medio rural. } \\
\text { - Importancia de la población } \\
\text { menor de } 15 \text { años (población } \\
\text { dependiente). } \\
\text { - Generalización del trabajo infantil. } \\
\text { - Desequilibrio entre la población } \\
\text { activa masculina y femenina. } \\
\text { - Tasa elevada de desempleo } \\
\text { urbano (sobre todo femenino). } \\
\text { - Importante número de licenciados } \\
\text { universitarios en paro. } \\
\text { - Éxodo rural. } \\
\text { - Abundante población por debajo } \\
\text { del umbral de la pobreza. } \\
\text { - Intensa emigración clandestina a } \\
\text { Europa. }\end{array}$ \\
\hline
\end{tabular}

Fuente: Elaboración propia. 


\section{Cuadro 5. Potencialidades y debilidades de la estructura productiva y del tejido empresarial de las regiones del norte de Marruecos}

\begin{tabular}{|c|c|c|}
\hline $\begin{array}{c}\text { Estructura } \\
\text { productiva y } \\
\text { tejido empresarial }\end{array}$ & Potencialidades & Debilidades \\
\hline Agricultura & $\begin{array}{l}\text { - Aptitud agrológica del suelo en } \\
\text { terrenos más o menos llanos. } \\
\text { - Condiciones climáticas } \\
\text { favorables a la actividad } \\
\text { agrícola. } \\
\text { - Desarrollo incipiente de } \\
\text { cultivos industriales. }\end{array}$ & 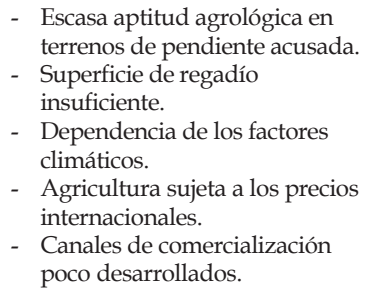 \\
\hline Pesca & $\begin{array}{l}\text { - Situación geográfica favorable. } \\
\text { - Infraestructuras portuarias } \\
\text { suficientes para autoabastecer } \\
\text { productos pesqueros. } \\
\text { - Contribución en el empleo } \\
\text { directo de las zonas rurales } \\
\text { próximas al litoral. }\end{array}$ & $\begin{array}{l}\text { - Incapacidad de explotar la } \\
\text { totalidad de los recursos } \\
\text { pesqueros como consecuencia } \\
\text { de la mediocridad de la flota y } \\
\text { de las instalaciones portuarias. } \\
\text { - Actividad exclusivamente } \\
\text { artesanal. }\end{array}$ \\
\hline Ganadería & 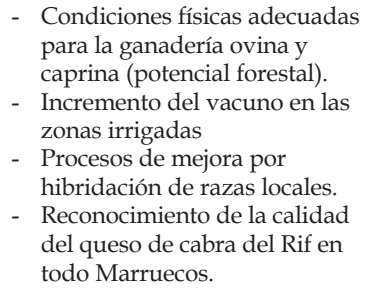 & $\begin{array}{l}\text { - Escasa potenciación de las } \\
\text { denominaciones de origen. } \\
\text { - Explotación ganadera } \\
\text { tradicional y rudimentaria. }\end{array}$ \\
\hline Minería & $\begin{array}{l}\text { - Importancia de las } \\
\text { exportaciones. } \\
\text { - Garantía de la producción } \\
\text { nacional de antimonio. }\end{array}$ & $\begin{array}{l}\text { - Riqueza minera modesta. } \\
\text { - Explotación irregular de las } \\
\text { minas. }\end{array}$ \\
\hline Industria & $\begin{array}{l}\text { - Sector de desarrollo económico } \\
\text { susceptible de consolidar la } \\
\text { estructura económica regional. } \\
\text { - Incremento de las inversiones } \\
\text { por parte del gobierno (Tánger } \\
\text { Free Zone). } \\
\text { - Importancia de la mano de obra } \\
\text { empleada de forma } \\
\text { permanente. } \\
\text { - Diversificación del tejido } \\
\text { industrial. }\end{array}$ & $\begin{array}{l}\text { - Elevado precio del terreno en } \\
\text { comparación con otros centros } \\
\text { industriales del país. } \\
\text { - «Fuga» de empresas hacia otras } \\
\text { regiones como consecuencia de } \\
\text { la falta de suelo industrial. } \\
\text { - } \quad \text { Personal poco cualificado } \\
\text { (mujeres en el textil). } \\
\text { - Degradación continua de las } \\
\text { infraestructuras de carreteras y } \\
\text { de las redes de saneamiento. }\end{array}$ \\
\hline
\end{tabular}


Continuación...

\begin{tabular}{|c|c|c|}
\hline $\begin{array}{c}\text { Estructura } \\
\text { productiva y } \\
\text { tejido empresarial }\end{array}$ & Potencialidades & Debilidades \\
\hline & & $\begin{array}{l}\text { - Reducida expansión del sector } \\
\text { como consecuencia de los } \\
\text { frecuentes cortes de agua } \\
\text { (sequía) y electricidad. } \\
\text { - Industria dependiente del Polo } \\
\text { de Casablanca para los } \\
\text { suministros de materias primas. } \\
\text { - Ausencia de legislación } \\
\text { referente a los residuos } \\
\text { industriales. } \\
\text { - Proyectos poco ambiciosos que } \\
\text { no implican una } \\
\text { transformación evidente de la } \\
\text { economía y de la sociedad. } \\
\text { - Disparidades regionales en } \\
\text { cuanto a la distribución de la } \\
\text { industria (Tánger vs. } \\
\text { Chefchaouen). } \\
\text { - Dominio de los subsectores que } \\
\text { no requieren tecnología } \\
\text { avanzada ni I+D (escaso VAB). }\end{array}$ \\
\hline Artesanía & $\begin{array}{l}\text { - Riqueza y diversidad de las } \\
\text { actividades artesanales (legado } \\
\text { patrimonial y artístico). } \\
\text { - Vinculación con el sector } \\
\text { turístico. } \\
\text { - Celebración anual de una } \\
\text { exposición de productos de } \\
\text { artesanía en la provincia de } \\
\text { Larache. }\end{array}$ & $\begin{array}{l}\text { - Actividad sometida a } \\
\text { fluctuaciones como } \\
\text { consecuencia de las dificultades } \\
\text { en el suministro de materias } \\
\text { primas, en la financiación y en } \\
\text { la comercialización del } \\
\text { producto en el mercado } \\
\text { nacional e internacional. } \\
\text { - Desvío de la mano de obra } \\
\text { hacia otros sectores. } \\
\text { - Regresión de las cooperativas } \\
\text { como consecuencia de la } \\
\text { ausencia de medidas de } \\
\text { fomento. } \\
\text { - Escaso control de calidad y del } \\
\text { precio de los productos } \\
\text { vendidos en los bazares, zocos } \\
\text { y establecimientos. }\end{array}$ \\
\hline Construcción & $\begin{array}{l}\text { - Tendencia creciente del sector } \\
\text { en los últimos años, con la } \\
\text { construcción de edificios de alto } \\
\text { standing. } \\
\text { - Gran número de mano de obra } \\
\text { empleada. }\end{array}$ & $\begin{array}{l}\text { - Importancia de la «economía } \\
\text { sumergida». } \\
\text { - Poca planificación urbana y } \\
\text { regional. } \\
\text { - Inseguridad laboral. }\end{array}$ \\
\hline Turismo & $\begin{array}{l}\text { - Situación privilegiada y } \\
\text { diversidad paisajística y } \\
\text { cultural. }\end{array}$ & $\begin{array}{l}\text { - Carácter estacionario de la } \\
\text { actividad turística (mayo- } \\
\text { septiembre). }\end{array}$ \\
\hline
\end{tabular}


Continuación...

\begin{tabular}{|c|c|c|}
\hline $\begin{array}{c}\text { Estructura } \\
\text { productiva y } \\
\text { tejido empresarial }\end{array}$ & Potencialidades & Debilidades \\
\hline & $\begin{array}{l}\text { - Fuente de divisas. } \\
\text { - Intensa generación de empleo } \\
\text { directo e indirecto. } \\
\text { - Sostenimiento de la actividad } \\
\text { pese a la coyuntura } \\
\text { internacional adversa. } \\
\text { - Equipamientos y alojamientos } \\
\text { suficientes para la captación } \\
\text { turística. }\end{array}$ & $\begin{array}{l}\text { Escaso control de la calidad y } \\
\text { del precio de los productos } \\
\text { vendidos en los bazares, zocos } \\
\text { y establecimientos. } \\
\text { - } \text { Insuficiente puesta en valor de } \\
\text { los recursos autóctonos, con } \\
\text { pésima organización. } \\
\text { - Fuertes desequilibrios } \\
\text { espaciales (litoral vs. interior). } \\
\text { - Escasez de infraestructuras y de } \\
\text { servicios turísticos. }\end{array}$ \\
\hline Comercio & $\begin{array}{l}\text { - Progresiva modernización de } \\
\text { las estructuras (control de } \\
\text { cambios, política de } \\
\text { inversiones, etc.) y apertura } \\
\text { económica al exterior. } \\
\text { - Relaciones con la Unión } \\
\text { Europea (especialmente, } \\
\text { Francia y España). } \\
\text { - Oportunidad de mercado para } \\
\text { las empresas españolas } \\
\text { (importaciones). }\end{array}$ & $\begin{array}{l}\text { - Desequilibrio de la balanza } \\
\text { comercial. } \\
\text { - Excesiva polarización de las } \\
\text { exportaciones en el continente } \\
\text { europeo. } \\
\text { - Concentración en grupos de } \\
\text { productos con reducido valor } \\
\text { añadido. } \\
\text { - Contrabando. }\end{array}$ \\
\hline Tejido empresarial & $\begin{array}{l}\text { - Agresivas inversiones } \\
\text { realizadas por el Estado y las } \\
\text { firmas extranjeras. } \\
\text { - Obtención de tecnología } \\
\text { compleja y construcción de } \\
\text { instalaciones grandes y } \\
\text { modernas. }\end{array}$ & $\begin{array}{l}\text { - Empresas con insuficiente } \\
\text { capacidad como para } \\
\text { interrelacionarse o crear canales } \\
\text { de comercialización. } \\
\text { - } \text { Adopción de una estrategia de } \\
\text { costes. } \\
\text { - Estructura productiva } \\
\text { dependiente de las materias } \\
\text { primas. } \\
\text { - Escasa cualificación de la mano } \\
\text { de obra. } \\
\text { - Gama de sectores poco } \\
\text { desarrollada. } \\
\text { - Déficit de maquinaria, servicios } \\
\text { a las empresas, etc. }\end{array}$ \\
\hline Sector bancario & $\begin{array}{l}\text { - Reestructuración y reconversión } \\
\text { del sector (mejor gestión y } \\
\text { control). } \\
\text { - Consolidación de las ayudas } \\
\text { bancarias como principal fuente } \\
\text { de financiación de la economía. } \\
\text { - Participación de filiales } \\
\text { extranjeras (accionarios). } \\
\text { - Importancia dentro del PIB. }\end{array}$ & $\begin{array}{l}\text { - Escasa cobertura de este tipo de } \\
\text { servicios (perjuicio para las } \\
\text { PYMES). } \\
\text { - Concentración de un tercio de } \\
\text { la actividad nacional en } \\
\text { Casablanca. }\end{array}$ \\
\hline
\end{tabular}

Fuente: Elaboración propia. 
La evolución de la política económica marroquí -desde los programas de ajuste estructural de la década de los ochenta, pasando por el proceso de liberalización y privatizaciones de los noventa- ha perjudicado a este espacio regional. Sin embargo, el nuevo marco de libre cambio (zonas de libre comercio con la Unión Europea y Estados Unidos) y la implantación de criterios sociales y locales (política social y el instrumento índice de desarrollo humano) benefician a estas regiones septentrionales en la actualidad, necesitadas como están de fomento, cohesión territorial y justicia social.

Por ello las medidas propiciadoras de desarrollo territorial deben ser útiles para construir un desarrollo humano local con base en los recursos del territorio. A partir de aquí, pueden hallarse nuevos incentivos ofreciendo a la población joven oportunidades de formación y empleo, mejorando la gestión del flujo migratorio, valorando el patrimonio cultural-natural y potenciando los recursos del territorio.

Las redes locales de relaciones tradicionales se presentan como nodo esencial para el desarrollo territorial y la instrumentación de la cooperación, con una mayor participación de la población. Para ello es necesaria la fluidez en la circulación de la información, el diálogo y la participación entre ciudadanos y administraciones públicas.

Se debe hacer de la cooperación descentralizada, tanto geográfica como socialmente, un instrumento para acentuar la prioridad del desarrollo territorial y la consecuente cohesión social.

Siguiendo la tesis de Blatter (2004), la situación de este espacio marroquí demuestra que Europa establece, para sus regiones fronterizas vecinas, políticas territoriales e institucionales que dan prioridad al "espacio de los lugares", individualizando cada país y sus regiones fronterizas para hacerlas partícipes de los beneficios de la integración económica. Estrategia diferenciada y opuesta a la que, según analiza Blatter, acontece en Norteamérica, en cuyas regiones fronterizas se van estableciendo una serie de redes y flujos transnacionales, muchas veces informales, en determinados sectores económicos, lo que pudiera entenderse como el "espacio de los flujos", con capacidad de transformación, pero obviando los condicionantes y las capacidades territoriales de los lugares. 
La teoría del "espacio de los lugares" aplicada a las relaciones fronterizas europeas (Blatter, 2004) toma cuerpo tanto en la Política Europea de Vecindad como en el Plan Director de Cooperación de la Agencia Española de Cooperación Internacional, ya que ambas plantean enfoques diferenciados por regiones y graduales en el cumplimiento de objetivos, con un avance monotorizado en el que es operativo el planteamiento del desarrollo territorial, entendido como desarrollo equilibrado social y territorialmente, endógeno, basado en recursos propios o locales, y sostenible desde la perspectiva ambiental.

Los nuevos instrumentos financieros que la Política Europea de Vecindad prevé a partir de 2007 hacen imprescindibles los proyectos conjuntos entre países (tanto de cooperación transfronteriza como de cooperación regional) con la idea de aplicar modalidades y procedimientos propios de los fondos estructurales de la Unión Europea, teniendo en cuenta debilidades y fortalezas. El camino propuesto se basa en la búsqueda del desarrollo (con crecimiento), incentivando la integración (superando bilateralidades), una correcta ordenación territorial y la superación de desequilibrios socioeconómicos entre países y regiones fronterizas, salvaguardando así los intereses estratégicos y geopolíticos.

\section{Bibliografía}

Alaoui Lamrani, A. y otros (2000), Région Tanger-Tétouan. Débat National sur l'Aménagement du Territoire. Eléments introductifs, Marruecos Direction de L'Aménagement du Territoire, Ministère de L'Aménagement du Territoire, de L'Environnement de l'Urbanisme, et de L'Habitat, Reino de Marruecos, 58 pp.

APDN (2005), Estrategia de desarrollo de las prefecturas y provincias del Norte del Reino, Reino de Marruecos, Agencia para la Promoción y el Desarrollo de las Prefecturas del Norte del Reino, www. apdn.ma

AECI (2005a), Plan Director de Cooperación, Dirección General de Planificación y Evaluación de Políticas para el Desarrollo. Ministerio de Asuntos Exteriores y de Cooperación, www.aeci.es 
AECI (2005b), Documento de Estrategia País. DEP Marruecos 2005-2008. Cooperación Española, Dirección General de Planificación y Evaluación de Políticas para el Desarrollo, Ministerio de Asuntos Exteriores y de Cooperación, www.aeci.es

Bel Adel, C. y J. Gómez Fayren (2000), "Migraciones y cooperación al desarrollo", Hacia un nuevo espacio euromediterráneo. III Encuentro Geografía Regional, Barcelona, pp. 295-302.

Blatter, J. (2004.), "From Spaces of Place to Spaces of Flows? Territorial and Functional Governance in Cross-border Regions in Europe and North America", International Journal Urban and Regional Research, volúmen 28, Septiembre,. pp. 530-548.

Castells, M. (1996), The rise of the network society, Oxford, Blackwell. CEE (2004), European Neighbourhood Policy. Strategy Paper, Bruselas, disponible en htpp:/ / europa.eu.int/comm/world/enp

Desrues, T. (2005), "Virtudes y límites de la sociedad civil como factor de cambio en Marruecos", en F. Izquierdo y T. Desrues Actas Primer Congreso del Foro de Investigadores del Mundo Árabe y Musulmán (FIMAM), Barcelona, Bellatera, p. 14.

El Houdaigui, R. (2005), "Le détroit de Gibraltar: d'une frontière conflictuelle à un espace transnational?", en F. Izquierdo y T. Desrues, Actas Primer Congreso del Foro de Investigadores del Mundo Árabe y Musulmán (FIMAM), Barcelona, Bellatera, p. 9.

Jerch, M. (2004), "Reformas económicas y la perspectiva de la liberación política en Marruecos", Información Comercial Española, 819, Madrid.

Jordá Borrell, R. M. (2002), “Contribución andaluza a la formación de un espacio fronterizo en la frontera hispanomarroquí", Estudios Fronterizos, vol. 3, núm. 5, pp. 77-92.

López García, B. y M. Berriane (2004), Atlas de la inmigración magrebí en España, Taller de Estudios Internacionales Mediterráneos, Madrid, Universidad Autónoma de Madrid, p. 526.

López Lara, E. (2001), “Diagnóstico territorial de las montañas del Rif (Marruecos). Propuesta de desarrollo territorial de un espacio subdesarrollado", Forma y función del territorio, Oviedo, Universidad de Oviedo, CeCodet, AGE y GEA, pp. 381-383. 
López Lara, E. (2005), “La imagen turística de Marruecos proporcionada por Internet: reinterpretando el orientalismo", Cuadernos de Turismo, 16, Murcia, pp. 123-134.

Martín, I. (2005), “Vulnerabilidades socioeconómicas en el Magreb (I). Los riesgos del chabolismo en Marruecos", ARI, 36, Real Instituto Elcano, www.realinstitutoelcano.org/analisis/705.asp (2006), "Marruecos, ¿las bases para un nuevo modelo de desarrollo? (I). La iniciativa nacional de Desarrollo Humano" ARI, 35, Real Instituto Elcano, www.realinstitutoelcano.org/analisis/ 935.asp

Ministère de l'Aménagement du Territoire, de l'Environnement de l'Urbanisme, et de l'Habitat (2000), Le territoire marrocain. Etat des lieux, Rabat, Reino de Marruecos, Direction de l'Aménagement du Territoire, p. 128.

Ministère de la Prévision Économique et de la Planification (2000), Plan de Développement Économique et Social (2000-2004), Rabat, Le Maroc.

Moré, I. (2003), “El escalón económico entre vecinos. El caso EspañaMarruecos", Documentos del Real Instituto Elcano, www. realinstitutoelcano.org/documentos/44.asp

Nogué, J. y J. L. Vilanova (1999), España en Marruecos, Lleidas Milenio, p. 570.

Ojeda García, R. (2002), “El proceso de regionalización en Marruecos", Revista de Fomento Social, 57, pp. 154-173.

Olmo García, E. (2006), "El futuro del sistema institucional de la Cooperación Española”, Revista CIDOB d' Afers Internacional, 72, Barcelona, pp. 67-83.

PNUD (2004), Arab Human Development. Report 2004. Towards freedom in the Arab World, United Nations Development Programme, Arab Fund for Economic and Social Development, p. 248, www.pnud. org.ma (2005), Gold Magreb (Gobernanza Local para el Desarrollo en el Magreb), Programa Gold Maroc, www.pnud.org.ma/Gold.asp (2006), Country Programme Document for the Kingdom of Morocco (2007-2011), www.pnud.org.ma 
PDTAM (2003), Programa de Desarrollo Transfronterizo Andalucía-Marruecos 2003-2006, Junta de Andalucía y Reino de Marruecos, p. 51, www.juntadeandalucia.es/documentos

Reino de Marruecos (2006), Informe del Cincuentenario; 50 años de desarrollo humano y perspectivas para 2025, www.rdh50.ma; documento síntesis, disponible en español en www.rdh50.ma/esp/ docsynthese. esp.pdf

Suárez de Viveros, J. L. (2002), “Jurisdicciones marítimas en el Estrecho de Gibraltar", Documentos del Real Instituto Elcano, www.realinstitutoelcano.org/documentos/44.asp

Tribak, A., E. López Lara, M. Laaouane y J. Miranda (2006), “Activités touristiques et développement durable dans un espace montagnard marocain: cas du Moyen Atlas Oriental (Maroc)", Turismo sostenible en zonas de montaña, Francia, Université de Pau et des Pays de l'Adour.

Valencia, R. (2004), "Marruecos: parámetros sociales, políticos y económicos y perspectivas de cooperación", Documentos de discusión, $n^{0}$ 1. CEDOC, Madrid, $46 \mathrm{pp}$. 